\section{Right vocal cord paralysis and mediastinal lymphadenopathy}

\section{CASE PRESENTATION}

A non-smoking 45-year-old white man presented with a globus sensation worsened by lying down, with no complaints of hoarseness or dysphonia. He denied fever, fatigue, cough, chest pain, sweats, weight loss, reflux, arthralgias, myalgias and rash. $\mathrm{He}$ also denied exposure to asbestosis, beryllium, silica, HIV or tuberculosis, but he reported a recent cat bite. Physical examination revealed normal vital signs, no cervical or supraclavicular lympadenopathy and a normal cardiorespiratory system. He was referred to the otolaryngology department. Laryngoscopy revealed right vocal cord paralysis. A CT scan of the neck/chest identified diffuse mediastinal lymphadenopathy without parenchymal changes (figures 1 and 2).

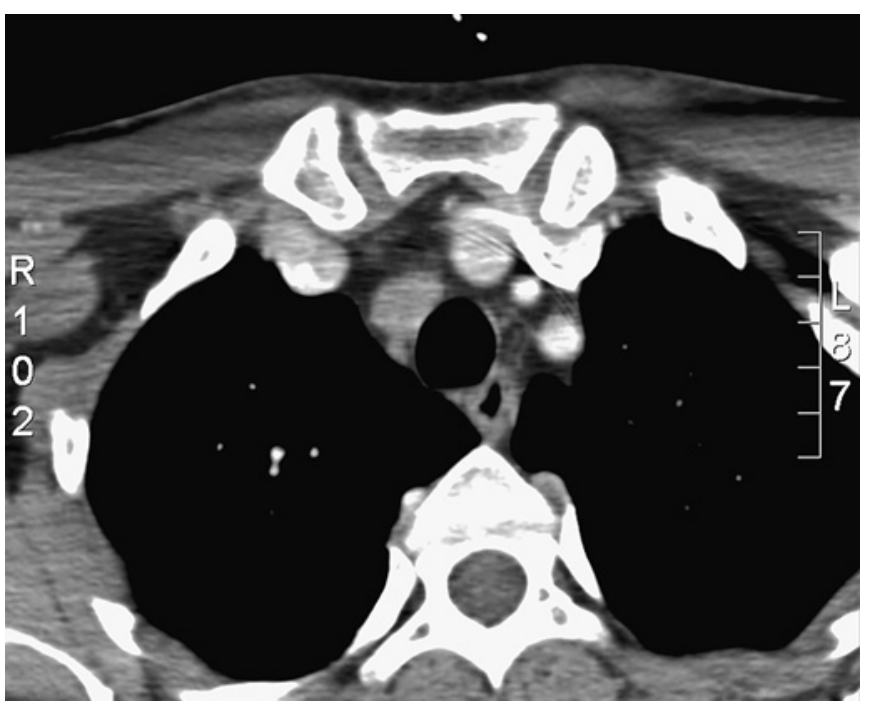

Figure 1 CT scan of high right paratracheal lymph node.

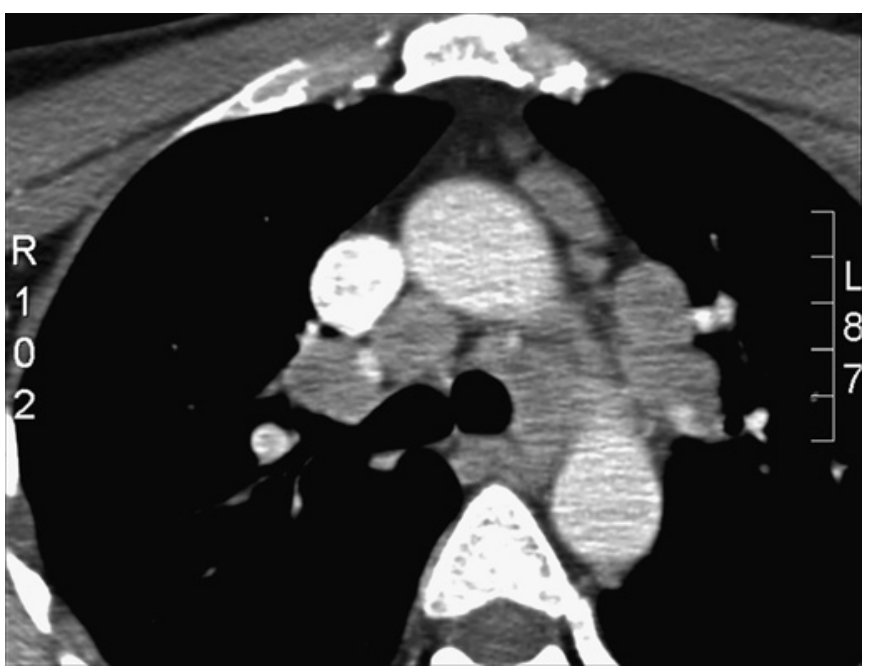

Figure 2 CT scan showing low paratracheal involvement.
A purified protein derivative test was negative. Endobronchial ultrasound (EBUS)-directed transbronchial needle aspirations (TBNA) were performed of the paratracheal and subcarinal lymph nodes (figure 3). Diagnostic bronchoscopy revealed no endobronchial lesions or mucosal abnormalities. Acid-fast bacilli studies were negative and flow cytometry detected no monoclonal lymphocytes. Bacterial and fungal cultures, cryptococcal/ histoplasma antigen, HIV and Bartonella serology were negative. ACE was $31 \mathrm{U} / 1$ (reference range 9-67 U/1). Pulmonary function testing revealed mild decreased diffusion capacity but was otherwise normal. Empirical steroid therapy failed to provide benefit and mediastinoscopic right paratracheal lymphadenectomy was subsequently conducted (figure 4).

\section{QUESTION}

What is the diagnosis?

See page 231 for answer

Michael Boyd, Subramanian Malaisamy, Susanti le, Edmundo Rubio

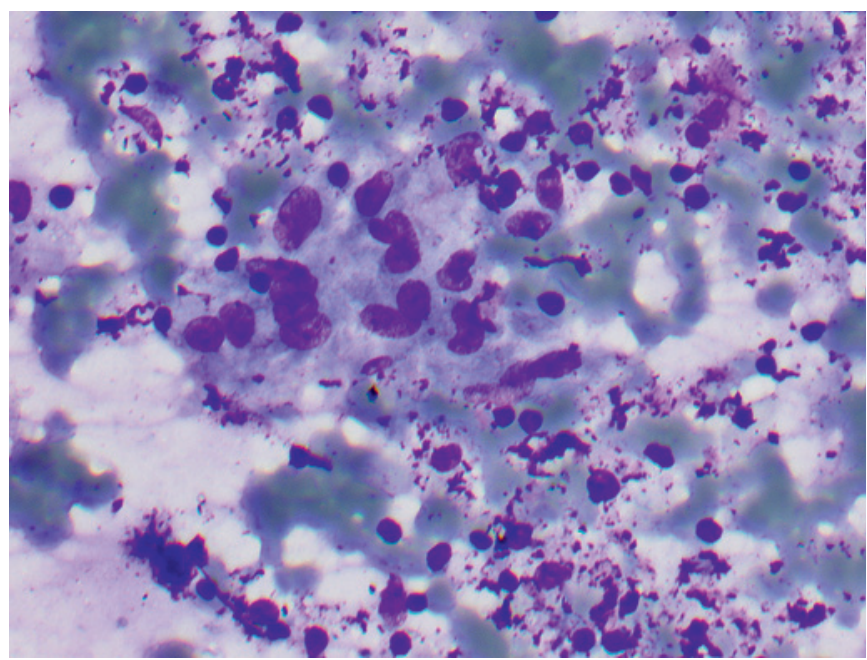

Figure 3 Endobronchial ultrasound-directed transbronchial needle aspiration cytology.

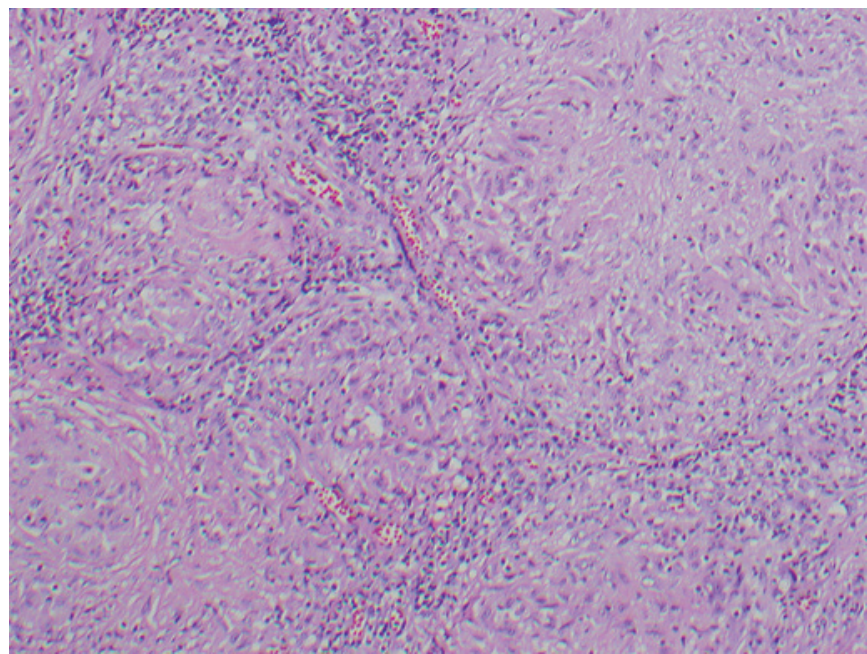

Figure 4 Mediastinoscopic lymphadenectomy histology. 
Virginia Tech Carilion School of Medicine, Section of Pulmonary, Critical Care, Environmental, and Sleep Medicine, Carilion Clinic, Virginia, USA

Correspondence to Dr Michael Boyd, Virginia Tech Carilion School of Medicine, Section of Pulmonary, Critical Care, Environmental, and Sleep Medicine, Carilion Clinic, 1906 Belleview Ave, Roanoke, VA 24014, USA; mbboyd@carilionclinic.org

Conflict interests None.
Patient consent Obtained.

Provenance and peer review Not commissioned; externally peer reviewed.

Published Online First 14 October 2010

Thorax 2011;66:211-212. doi:10.1136/thx.2010.140012 
promoting AE. AIPF also gives new insight into the key role of locoregional factors in the expansion of pulmonary fibrosis. TLCO may not be adapted to evaluate the severity of this particular form of IPF. Further studies are needed to assess more clearly the frequency and specific risk factors for AIPF and to determine the real impact of this form of IPF on clinical practice.

Competing interests DV has received consultancy fees from Intermune, Actelion and Sanofi (less than $\$ 4000$ in the last 5 years) and expenses from AstraZenica, Glaxo, Boehringer and Nycomed for travel and accommodation at ATS, ERS and CPLF meetings.

Ethics approval This study was conducted with the approval of the institutional review board.

Provenance and peer review Not commissioned; externally peer reviewed.

\section{REFERENCES}

1. American Thoracic Society. ATS/ERS international consensus classification of idiopathic interstitial pneumonias. Am J Respir Crit Care Med 2002;165:277-304.

2. Collard HR, Moore BB, Flaherty KR, et al. Acute exacerbations of idiopathic pulmonary fibrosis. Am J Respir Crit Care Med 2007;176:636-43.

3. Henry JP, Lenaerts A, Ligny G. [Diagnosis and treatment of gastroesophageal reflux in the adult: guidelines recommended by French and Belgian consensus]. Rev Med Brux 2001;22:27-32.

4. Akira M, Hamada H, Sakatani M, et al. CT findings during phase of accelerated deterioration in patients with idiopathic pulmonary fibrosis. AJR Am J Roentgenol 1997; 168:79-83.

5. Wells AU, Desai SR, Rubens MB, et al. Idiopathic pulmonary fibrosis: a composite physiologic index derived from disease extent observed by computed tomography. Am J Respir Crit Care Med 2003;167:962-9.

6. Raghu G. The role of gastroesophageal reflux in idiopathic pulmonary fibrosis. Am J Med 2003;115(Suppl 3A):60S-4.

7. Raghu G, Freudenberger TD, Yang S, et al. High prevalence of abnormal acid gastrooesophageal reflux in idiopathic pulmonary fibrosis. Eur Respir J 2006;27:136-42.

8. Sweet MP, Patti MG, Hoopes C, et al. Gastro-oesophageal reflux and aspiration in patients with advanced lung disease. Thorax 2009;64:167-73.

9. Savarino E, Bazzica M, Zentilin P, et al. Gastroesophageal reflux and pulmonary fibrosis in scleroderma: a study using pH-impedance monitoring. Am J Respir Crit Care Med 2009;179:408-13.
10. Fujiwara Y, Machida A, Watanabe $Y$, et al. Association between dinner-to-bed time and gastro-esophageal reflux disease. Am J Gastroenterol 2005;100:2633-6.

11. Piesman M, Hwang I, Maydonovitch C, et al. Nocturnal reflux episodes following the administration of a standardized meal. Does timing matter? Am J Gastroenterol 2007:102:2128-34.

12. Popper $\mathbf{H}$, Juettner $F$, Pinter J. The gastric juice aspiration syndrome (Mendelson syndrome). Aspects of pathogenesis and treatment in the pig. Virchows Arch A Pathol Anat Histopathol 1986;409:105-17.

13. Ahmad F, Ritzenthaler J, Roman J. Pepsin in gastric fluid promotes epithelial mesenchymal transformation: implications for understanding the role of reflux in pulmonary fibrosis. Am J Respir Crit Care Med 2009;179:A5311.

14. Cool CD, Groshong SD, Rai PR, et al. Fibroblast foci are not discrete sites of lung injury or repair: the fibroblast reticulum. Am J Respir Crit Care Med 2006:174:654-8

15. Decologne N, Kolb M, Margetts PJ, et al. TGF-beta1 induces progressive pleural scarring and subpleural fibrosis. J Immunol 2007;179:6043-51.

16. Tzouvelekis A, Anevlavis S, Bouros D. Angiogenesis in interstitial lung diseases: a pathogenetic hallmark or a bystander? Respir Res 2006; 7:82.

17. Chong S, Kim TS, Chung MP, et al. Unilateral usual interstitial pneumonia associated with sarcoma of the pulmonary artery. AJR Am J Roentgenol 2007;189 W221-3.

18. Ryu DS, Ahn JH, Choi SJ, et al. Congenital absence of the right interlobar pulmonary artery: HRCT findings. J Thorac Imaging 2008;23:292-4.

19. Kim DS, Park JH, Park BK, et al. Acute exacerbation of idiopathic pulmonary fibrosis: frequency and clinical features. Eur Respir J 2006;27:143-50.

20. Ware LB, Matthay MA. The acute respiratory distress syndrome. N Engl J Med 2000:342:1334-49.

21. Terada K, Muro S, Sato $\mathrm{S}$, et al. Impact of gastro-oesophageal reflux disease symptoms on COPD exacerbation. Thorax 2008;63:951-5.

22. Akira M, Kozuka T, Yamamoto S, et al. Computed tomography findings in acute exacerbation of idiopathic pulmonary fibrosis. Am J Respir Crit Care Med 2008:178:372-8.

23. Wells $\mathbf{A U}$, King $A D$, Rubens $M B$, et al. Lone cryptogenic fibrosing alveolitis: a functional-morphologic correlation based on extent of disease on thin-section computed tomography. Am J Respir Crit Care Med 1997;155:1367-75.

24. West JB, Dollery CT, Hugh-Jones P. The use of radioactive carbon dioxide to measure regional blood flow in the lungs of patients with pulmonary disease. J Clin Invest 1961:40:1-12

25. Nunes H, Carton Z, Cottin V, et al. A French national prospective cohort of patients with Idiopathic Pulmonary Fibrosis (IPF): demographic characteristics. Am J Respir Crit Care Med 2009;179:A2981.

\section{ANSWER}

From question on page 211

Non-caseating granulomas were identified on cytological and histological examination consistent with a diagnosis of sarcoidosis (figures 3 and 4). Sarcoidosis-associated vocal cord paralysis is uncommon. In general, vocal cord paralysis is usually bilateral or left-sided, probably due to decreased lymphatic drainage. In sarcoidosis, isolated right vocal cord paralysis has never been reported. Granulomatous invasion of the laryngeal nerves (perineuritis) and sarcoidosis-related cranial polyneuritis resulting in bilateral vocal cord paralysis have been reported rarely. ${ }^{1}$ Reports of unilateral left vocal cord paralysis are more common and are probably caused by compression by the bulky mediastinal disease on the left recurrent nerve at the level of the aorta. With a presumptive diagnosis of sarcoidosis based on the initial EBUS-TBNA cytology, oral steroids were administered for 2 months. The patient experienced no symptomatic improvement.

Studies suggest that the diagnostic accuracy of EBUS-TBNA in sarcoidosis is $85-91 \%{ }^{2}$. Although the patient's diagnosis was felt to be accurate, there remained concerns of a missed carcinoma. Sarcoid-like reactions can occur in the regional lymph nodes of carcinomas with a frequency of $4.4 \%{ }^{3}$ We also considered the possible benefit of lymphadenectomy in alleviating the compressive effects of the right paratracheal node, despite the prolonged course of nerve compression. Similarly, left recurrent laryngeal nerve palsy associated with silicosis improved after 15 weeks following mediastinoscopic lymphadenectomy. ${ }^{4}$ The patient's concern about malignancy and the potential therapeutic benefit of lymphadenectomy prompted mediastinoscopy. Mediastinoscopy (with a reported diagnostic accuracy in stage I or II sarcoidosis of $82-97 \%$ ) confirmed the patient's diagnosis. ${ }^{5}$ Six months after complete right paratracheal lymphadenectomy, both the globus sensation and right vocal cord function had improved. Given the patient's improvement with nodal resection, we suspect in this case the vocal cord paralysis was caused by nerve compression, reinforcing the need for decompression even in late stages (figure 1).

Thorax 2011;66:231. doi:10.1136/thx.2010.140012

\section{REFERENCES}

1. Witt RL. Sarcoidosis presenting as bilateral vocal fold paralysis. J Voice 2003;17:265-8.

2. Wong M, Yasufuku K, Nakajima T, et al. Endobronchial ultrasound: new insight for the diagnosis of sarcoidosis. Eur Respir J 2007;29:1182-6.

3. American Thoracic Society. ATS statement on sarcoidosis. Am J Respir Crit Care Med 1999;160:736-55.

4. Lardinois D, Gugger $\mathrm{M}$, Balmer $\mathrm{M}$, et al. Left recurrent laryngeal nerve palsy associated with silicosis. Eur Respir J 1999;14:720-2

5. Porte H, Roumilhac D, Eraldi L, et al. The role of mediastinoscopy in the diagnosis of mediastinal lymphadenopathy. Eur J Cardiothorac Surg 1998;13:196-9. 